Check for updates

Cite this: RSC Adv., 2017, 7, 48766

Received 18th August 2017

Accepted 10th October 2017

DOI: 10.1039/c7ra09163j

rsc.li/rsc-advances

\section{Tribochemistry and thermo-oxidative stability of halogen-free ionic liquids $\uparrow$}

\begin{abstract}
Vladimir Totolin, (D) ${ }^{* a}$ Lucia Pisarova, ${ }^{a}$ Nicole Dörr ${ }^{a}$ and Ichiro Minami ${ }^{b}$
Heat generation by friction during machine operation causes thermo-oxidative degradation and evaporation of lubricants which in turn generates volatiles. Therefore, having an excellent thermooxidative stability is one of the desired prerequisites for the applicability of lubricants in tribological systems. This study reports new insights regarding the thermo-oxidative stability of halogen-free roomtemperature ionic liquids (RTILs) as well as fundamental changes in the tribofilm's composition that have a positive impact on their tribological performance at elevated temperatures. In this context, the formation of binary iron phosphates/phosphides based tribofilms from a phosphonium phosphate-based RTIL has been reported for the first time. This RTIL significantly enhances both thermo-oxidative stability and tribological performance of alkylborane-imidazole complexes. A beneficial effect between this RTIL and a conventional friction modifier led to enhanced anti-wear properties supported by the presence of iron phosphide/phosphate tribofilms on the disc surfaces, as detected by XPS.
\end{abstract}

\section{Introduction}

The on-going trend of improving the energy efficiency, fuel economy and long-term reliability of modern machinery has drawn tremendous interest for the development of high performance lubricants and/or lubricant additives that can significantly reduce the friction and wear of mechanical devices with moving parts, while posing less risk to the environment. In this context, room-temperature ionic liquids (RTILs) have been explored as novel lubricants since 2001 (ref. 1) and are currently subject of great interest for lubrication in both fundamental and applied research..$^{2-7}$ Based on their unique and tunable physico-chemical properties (low to negligible vapour pressure, good thermal stability, inherent polarity, low melting point, etc.), RTILs have also been studied as versatile lubricants and/or lubricant additives for various engineering surfaces under elevated temperatures ${ }^{8-11}$ and vacuum, ${ }^{12-14}$ where the use of conventional lubricants is limited. Therefore, RTILs are advanced, technological solvents that can be designed to fit a particular application. However, the perception that all RTILs are green solvents may lead to inappropriate experimental design and/or utilization of these compounds..$^{15}$

Several types of RTILs with imidazolium, ammonium, phosphonium, pyridinium, pyrrolidinium, etc., as cations and halides, hexafluorophosphate $\left(\mathrm{PF}_{6}{ }^{-}\right)$, tetrafluoroborate $\left(\mathrm{BF}_{4}{ }^{-}\right)$,

${ }^{a}$ AC2T research GmbH, Viktor-Kaplan-Strasse 2/C, 2700 Wiener Neustadt, Austria. E-mail: Vladimir.Totolin@ac2t.at

${ }^{b}$ Division of Machine Elements, Luleå University of Technology, Luleå, Sweden

$\dagger$ Electronic supplementary information (ESI) available. See DOI: 10.1039/c7ra09163j perchlorate $\left(\mathrm{ClO}_{4}^{-}\right), \quad$ bis(pentafluoroethanesulfonyl)imide $\left(\mathrm{BETI}^{-}\right)$, bis(trifluoromethylsulfonyl)imide $\left(\mathrm{NTf}_{2}{ }^{-}\right)$, tris(pentafluoroethyl)trifluorophosphate ( $\left.\mathrm{FAP}^{-}\right)$, etc., as anions have been evaluated for their tribological properties, ${ }^{1-6,16-21}$ thermal stability and corrosiveness. ${ }^{22-25}$ Most imidazolium and ammonium salts with shorter alkyl chains tend to absorb water when exposed to moisture. ${ }^{26}$ Moreover, it has been reported that the decomposition of halogen containing anions (especially $\mathrm{PF}_{6}{ }^{-}$ and $\mathrm{BF}_{4}{ }^{-}$) either under tribological conditions or via hydrolysis by water trapped molecules yields hazardous by-products (HF, etc.) that can cause (tribo)corrosion, thus resulting in increased friction and wear on both steel and aluminium surfaces..$^{15,27,28}$ In addition, the high costs associated with the production and disposal of the halogenated RTILs (especially fluorine-based precursors) represent big challenges for their use in industrial applications. Therefore, halogen-free RTILs have recently become a topic of great interest in terms of cost-effective and environmentally-acceptable lubricant development.

Initial studies on halogen-free ionic liquids (ILs) included the use of organic phosphate anions such as dimethylphosphate and diphenylphosphate that have shown similar or even lower friction and wear than $\mathrm{Tf}_{2} \mathrm{~N}^{-}$and $\mathrm{FAP}^{-}$for both steel/steel and aluminium/steel systems. ${ }^{18,29,30}$ Moreover, alkylborate dithiophosphates have also been investigated with the main goal of combining $\mathrm{B}, \mathrm{S}$ and $\mathrm{P}$ atoms in one organic molecule aiming at improving tribological and environmental performance of both dialkyldithiophosphates and borate esters. ${ }^{31}$

However, the limited solubility of RTILs (whether halogenated or not) in non-polar hydrocarbon oils represents one of the bottleneck limiting factors for their use in tribological applications. Therefore, in order to overcome the solubility challenge, 
some recent studies focused on lubricant mixtures composed of alkylborane-imidazole complexes blended with halogenated and halogen-free RTILs. ${ }^{32,33}$ It has been reported that these complexes (also known as Lewis acid-base complexes) have some physical properties (viscosity, glass transition temperature and melting point) that are comparable to those of conventional RTILs. ${ }^{34}$ Moreover, due to the strong coordination of nitrogen to boron, these complexes possess a considerable amount of charge that allows them to act as an aprotic polar solvent capable of dissolving various substrates or salts. ${ }^{32,34}$ It was found that phosphate-based tribofilms from phosphonium phosphate IL exhibit better tribological properties than fluoride-based tribofilms from halogenated IL. Other studies on oil miscible phosphonium phosphate ILs as lubricant additives reported comparable or even superior anti-wear and anti-scuffing properties of those ILs when compared to a conventional ZDDP additive in a polyalphaolefin base oil. ${ }^{35-38}$ In case of phosphonium-based ILs, their bulky structure with a higher number of alkyl groups leads to weakening of the Coulomb force between the anion and cation, thus improving their affinity with non-polar molecules (such as hydrocarbons). This makes them fully soluble in both mineral and synthetic oils.

Other tribological studies involving bis(salicylato)borate anion combined with imidazolium and ammonium ILs have also been reported..$^{39-41}$ However, the authors were not able to provide a plausible explanation about the ILs lubrication mechanism which was attributed to the "complexity of boron chemistry". Nevertheless, this was clarified by other research groups that suggested an anti-wear mechanism that involves formation of thin layers of boron trioxide $\left(\mathrm{B}_{2} \mathrm{O}_{3}\right)$ on the metal surfaces. ${ }^{42-44}$

Some relatively recent advancements in tribology of halogenfree ILs using phosphonium cations, ${ }^{45}$ ammonium-organoborate ILs $^{46}$ as well as ILs derived from amino acids ${ }^{47}$ have also been reported. Most of the ILs synthesized and investigated in these studies showed superior tribological performance whether used as neat liquids or as lubricant additives.

The heat generation by friction during machine operation causes thermo-oxidative degradation and evaporation of lubricants which generates volatile fragments. ${ }^{22}$ Therefore, having an excellent thermo-oxidative stability is one of the desired prerequisites for the applicability of lubricants in tribological systems. In contrast to well explored long-term behaviour of conventional lubricants, there is still a lack of knowledge in case of the ILs long-term performance. ${ }^{23}$ Some studies showed that the thermal stability and corrosion properties of imidazolium and ammonium-based ILs with $\mathrm{Tf}_{2} \mathrm{~N}^{-}$and methanesulfonate anions depend on the combination of cation and anion. ${ }^{22,23,48}$ Furthermore, an intermolecular transmethylation in ammonium-based ILs was identified under long term thermooxidative stress. It was suggested that the altered products from the ILs can negatively influence their tribological performance due to thermal degradation. ${ }^{24}$

While our previous results obtained using alkylboraneimidazole complexes blended with phosphonium phosphate IL as additive are promising, ${ }^{32,33}$ this current study reports new insights regarding the thermo-oxidative stability and fundamental changes in the tribofilm's composition that have a positive impact on the ILs tribological performance at elevated temperatures. It has been reported previously that iron phosphide tribofilms which are occasionally formed from phosphonate esters improve the anti-wear properties of lubricants. ${ }^{49-51}$ Moreover, there is no evidence in literature of phosphide tribofilms formed from phosphonium phosphate ILs.

Therefore, to the best of our knowledge, this is the first study reporting the formation of iron phosphide species from phosphonium phosphate ILs. In order to correlate the role of the tribofilms formed on the surface with wear behaviour, the topography of the rubbed surfaces was examined using white light confocal microscopy and the chemical nature of the tribofilms was investigated by X-ray photoelectron spectroscopy (XPS).

\section{Experimental section}

\subsection{Materials and additive chemistry}

$\mathrm{N}$-Allylimidazole tributylborane (hereafter referred to as A) and $\mathrm{N}$-ethylimidazole tributylborane (hereafter referred to as E) were purchased from Kanto Chemical Co., Inc. (Tokyo, Japan) and were blended into a $1 \mathrm{~g}$ mixture $(1: 1$ ratio), which was used as a carrier fluid. Tributylmethylphosphonium dimethylphosphate (hereafter referred to as $\mathrm{P}$ ) purchased from Nippon Chemical Industry Co., Ltd. (Tokyo, Japan) was employed as anti-wear additive at concentrations of $100 \mathrm{mM}$ and $1000 \mathrm{mM}$. 4,4'-Methylene-bis(2,6-di-tert-butylphenol) (hereafter referred to as AO) from SI Group, Inc. (Schenectady, NY) and glycerol mono-oleate (hereafter referred to as FM) commercially available from INOLEX (Philadelphia, PA) were used as antioxidant (100 mM concentration) and friction modifier $(50 \mathrm{mM}$ concentration), respectively. The chemicals were used as received. The molecular structures of the individual lubricant components are displayed in Fig. 1.

\subsection{Physico-chemical characterization of ionic liquids}

The kinematic viscosities at 40 and $100{ }^{\circ} \mathrm{C}$ were measured with a Stabinger viscometer SVM 3000 (Anton Paar GmbH, Graz,

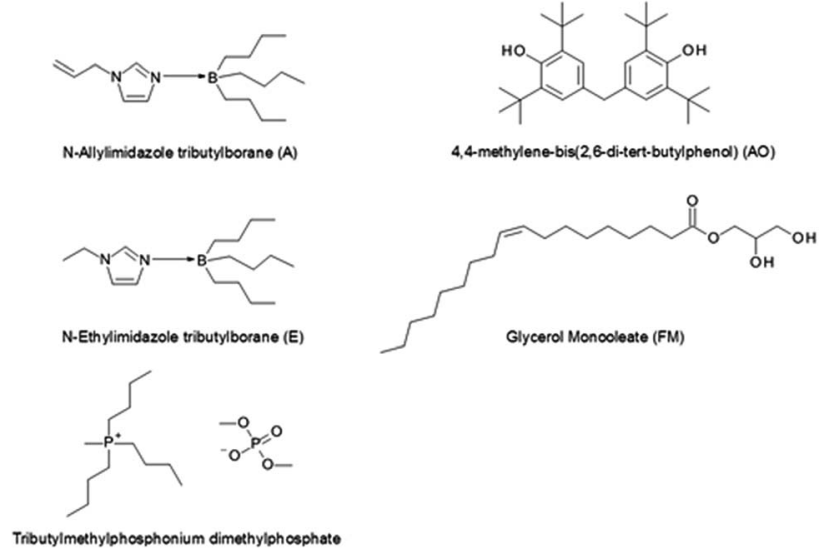

Fig. 1 Molecular structures of the lubricant components. 
Austria). The viscosity index was determined according to the ASTM D2270-04 standard. The water content (as a result of RTIL moisture uptake) was determined using Karl-Fisher titration method.

\subsection{Thermo-oxidative stability of ionic liquids}

Artificial alteration experiments were performed to get a better understanding of RTILs structural changes during thermooxidative stress and its impact on the tribological performance. Sample aliquots of $1 \mathrm{~g}$ were transferred to non-sealed glass vials which were placed in a laboratory oven and exposed to $100{ }^{\circ} \mathrm{C}$ for a duration of 1,3 and 7 days. The applied temperature was adjusted to the one used during the tribological experiments. The sample's weight was measured before and after the artificial alteration experiments using a high precision laboratory balance.

The visual changes in selected samples were analysed by ultraviolet-visible (UV-VIS) light analysis using an Analytik Jena SPECORD 50 UV-VIS spectrometer (Jena, Germany). A $1 \mathrm{~mm}$ cuvette was used and the samples were diluted in methanol.

Structural changes as a result of thermo-oxidative stress were monitored by Attenuated Total Reflectance Fourier Transform Infrared analysis (ATR-FTIR) using a Bruker Tensor 27 spectrometer (Esslingen, Germany) equipped with a diamond crystal.

\subsection{Evaluation of tribological properties of ionic liquids}

The tribological evaluation of the IL mixtures on AISI 52100 steel-steel contact was conducted with a ball-on-flat model contact in a Schwing-Reib-Verschleiss (SRV) tribometer (Optimol Instruments Prüftechnik GmbH, Munich, Germany) operated in oscillating reciprocating motion. Fresh steel specimens were used for each lubricant sample. The specimens were subsequently washed in three different solvents (toluene, isopropanol and petroleum ether) for ten minutes each, using an ultrasound bath, before and after the tribological experiments. The lubricant quantity $(0.2 \mathrm{~mL})$ was adjusted using a glass pipette to ensure fully immersed tribocontacts for the entire duration of the experiment. The coefficient of friction (COF) was monitored as a function of time. At least three repetitions were performed for each investigated IL mixture and the results were averaged. The SRV tribometer parameters are listed in Table 1.

\subsection{Surface topography and chemical composition of the tribofilms}

After each tribological experiment, the topography of the worn surfaces was analyzed using a usurf white light confocal microscope (NanoFocus AG, Oberhausen, Germany). The volume of the wear scars acquired on both tribo-pairs (ball and disc) was calculated with MATLAB software, as previously described in our earlier works. ${ }^{32,33,52}$ An ideal surface was defined as reference surface which was flat for the discs and spherical for the balls. The volume of the removed material was calculated by subtracting the value between the reference surface and the measured worn surface.
Table 1 Tribometrical conditions

\begin{tabular}{|c|c|c|c|}
\hline \multirow{7}{*}{$\begin{array}{l}\text { SRV rig } \\
\text { parameters }\end{array}$} & & Applied load (N) & 150 \\
\hline & & Average Hertz contact stress (GPa) & 1.6 \\
\hline & & Frequency $(\mathrm{Hz})$ & 50 \\
\hline & & Stroke $(\mathrm{mm})$ & 1 \\
\hline & & Oil temperature $\left({ }^{\circ} \mathrm{C}\right)$ & 100 \\
\hline & & Duration (min) & 60 \\
\hline & & Fluid quantity $(\mathrm{mL})$ & 0.2 \\
\hline \multirow[t]{8}{*}{ Specimens } & Ball & Material & AISI 52100 \\
\hline & & Diameter (mm) & 10 \\
\hline & & Hardness (HRc) & 60 \\
\hline & & Surface roughness $R_{\mathrm{a}}(\mu \mathrm{m})$ & 0.025 \\
\hline & Disc & Material & AISI 52100 \\
\hline & & Size $(\mathrm{mm})$ & $\varnothing 24 \times 7.9$ \\
\hline & & Hardness (HRc) & 62 \\
\hline & & Surface roughness $R_{\mathrm{z}}(\mu \mathrm{m})$ & $0.45-0.65$ \\
\hline
\end{tabular}

The chemical analysis of the tribofilms formed on the discs was performed by XPS. The analyses were conducted using a Thetaprobe (Thermo Fisher Scientific, East Grinstead, United Kingdom) equipped with a monochromatic Al $\mathrm{K} \alpha \mathrm{X}$-ray source $(h \nu=1486.6 \mathrm{eV})$ and a hemispherical analyser. The measurements were performed at a base pressure of $2 \times 10^{-9} \mathrm{mbar}$. The analysed spot size diameter was $300 \mu \mathrm{m}$, and the pass energies used were $200 \mathrm{eV}$ for the survey spectra and $50 \mathrm{eV}$ for the high resolution spectra, respectively. Afterwards, the spectra were processed by a software (Thermo Fisher Scientific Avantage Data System, East Grinstead, United Kingdom), using Gaussian-Lorentzian peak fitting. All the high resolution spectra were referenced to the adventitious carbon (C 1s binding energy of $284.8 \mathrm{eV}$ ).

\section{Results and discussion}

\subsection{Physico-chemical characterization of ionic liquids}

The physico-chemical properties of the selected neat fluids A, E and $\mathrm{P}$ are given in Table 2 . $\mathrm{P}$ exhibited much higher viscosity when compared to the other two fluids (A and E) at both measured temperatures. It has been reported that in ILs, the viscosity increases with the increase in the chain length ${ }^{2}$ and that the ILs viscosities are governed essentially by van der Waals forces and hydrogen bonds. ${ }^{53}$ Therefore, an increase in viscosity for $\mathrm{P}$ could be attributed to an increase in van der Waals and Coulomb interactions from the alkyl chains due to reduced rotation freedom. ${ }^{53}$

\subsection{Thermo-oxidation of ionic liquids}

The photographs of the IL samples after the artificial alteration experiments are shown in Fig. 2. Except for the phosphonium phosphate IL, which preserved its colour and exhibited a honeylike rheological behaviour, all the other IL samples formed dark-solid deposits after 7 days at $100{ }^{\circ} \mathrm{C}$. The relationship between molecular structure and volatility of neat ILs was clearly observed during the artificial alteration experiments as displayed in Fig. 3.

It is evident that phosphonium phosphate alone is much more stable than imidazole-tributylborane complexes, which 
Table 2 Physico-chemical properties of the neat fluids A, E and P

\begin{tabular}{|c|c|c|c|c|c|c|}
\hline \multirow[b]{2}{*}{ Sample } & \multirow[b]{2}{*}{ Abbreviation } & \multicolumn{2}{|c|}{$\begin{array}{l}\text { Viscosity } \\
\left(\mathrm{mm}^{2} \mathrm{~s}^{-1}\right)\end{array}$} & \multirow{2}{*}{$\begin{array}{l}\text { Viscosity index } \\
\text { (VI) }\end{array}$} & \multirow[b]{2}{*}{ Purity (\%) } & \multirow{2}{*}{$\begin{array}{l}\text { Water content } \\
(\mathrm{wt} \%)\end{array}$} \\
\hline & & $40{ }^{\circ} \mathrm{C}$ & $100^{\circ} \mathrm{C}$ & & & \\
\hline$N$-Allylimidazole tributylborane & A & 23.6 & 3.7 & -28.2 & $>97.0$ & 2.6 \\
\hline$N$-Ethylimidazole tributylborane & E & 26.7 & 3.8 & -67.4 & $>97.0$ & 2.5 \\
\hline Tributylmethyl-phosphonium & $P$ & 185 & 15.1 & 80.0 & 98.6 & 0.5 \\
\hline
\end{tabular}

dimethylphosphate

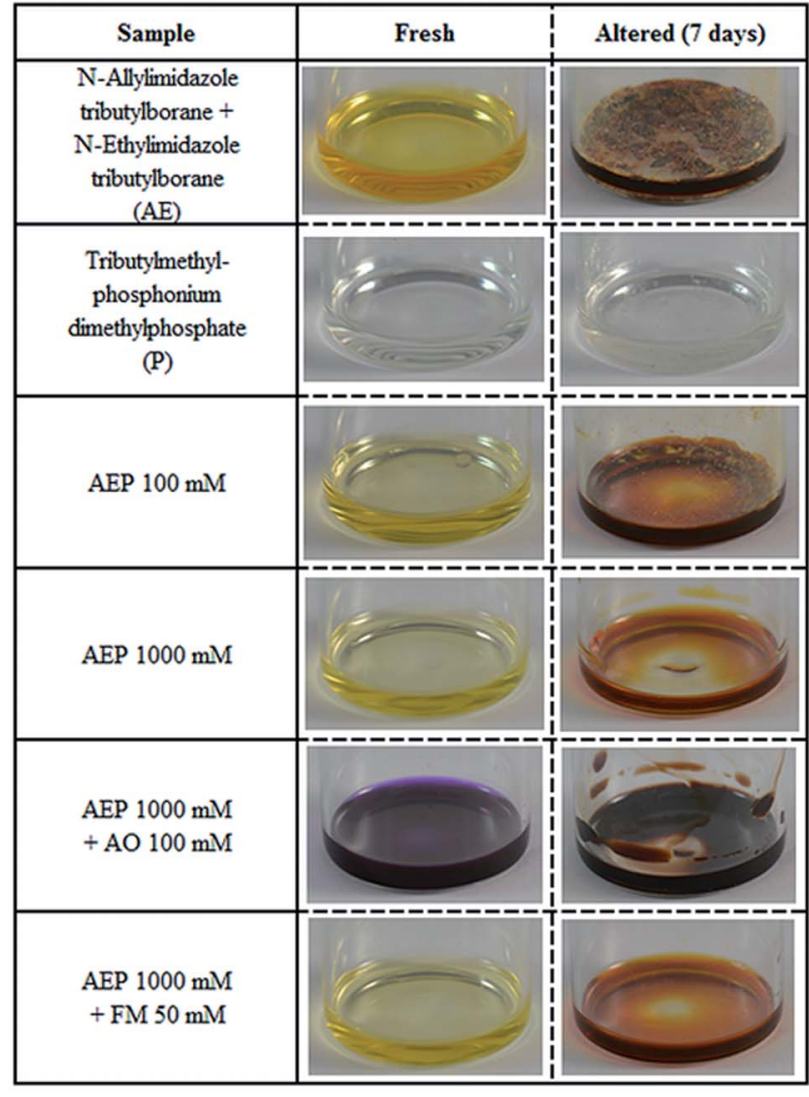

Fig. 2 Thermo-oxidatively stressed samples $\left(100^{\circ} \mathrm{C}\right.$ for 7 days).

can be attributed to their different chemistry. Almost no weight loss was detected for the phosphonium phosphate IL, where strong Coulomb forces are present.

The increasing content of $\mathrm{P}$ improved the thermo-oxidative stability of AE mixture due to the ability of the phosphate group to form an oxygen barrier between the oil and air interface $^{56}$ as well as the ability of organophosphorus compounds to decompose the peroxides, thus controlling the oxidative degradation of lubricants. ${ }^{57}$ This trend was also observed during the $1^{\text {st }}$ and $3^{\text {rd }}$ day of the experiments, when AEP $1000 \mathrm{mM}$ always led to lower weight loss when compared to AEP $100 \mathrm{mM}$ (as shown in the ESI, Fig. S1†). It is therefore suggested that the phosphonium phosphate IL possess antioxidant properties, and that the type and the amount of IL are equally important considerations for the formulation of IL lubricants.

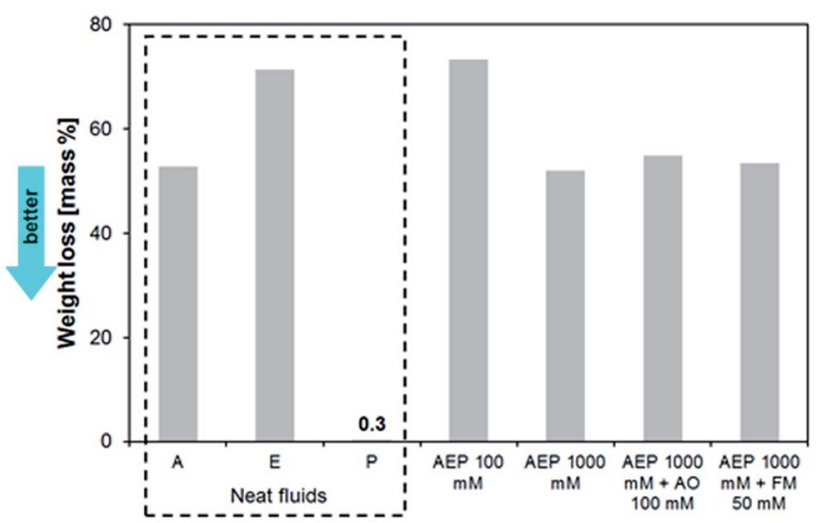

Fig. 3 Weight loss at constant temperature of $100{ }^{\circ} \mathrm{C}$ for 7 days.

On the other hand, the mixture with the conventional antioxidant (AEP $1000 \mathrm{mM}+\mathrm{AO} 100 \mathrm{mM}$ ) showed higher weight loss during the $1^{\text {st }}, 3^{\text {rd }}$ and $7^{\text {th }}$ day of experiments. Surprisingly, upon addition of AO to the AEP $1000 \mathrm{mM}$ mixture, unexpected colour change occurred, as observed in Fig. 2. It is suggested, that a possible ionic exchange between $\mathrm{P}$ and AO could yield a phenoxy radical derived from phenol by loss of a hydrogen atom. This phenoxy radical could shift the UV absorbance leading to visible colour change.

Weight loss after the addition of the FM to AEP $1000 \mathrm{mM}$ mixture was slightly better after $1^{\text {st }}$ and $3^{\text {rd }}$ day at $100{ }^{\circ} \mathrm{C}$ when compared to the AEP $1000 \mathrm{mM}$ mixture (Fig. S1†). However during the $7^{\text {th }}$ day, the antioxidant performance worsened, thus suggesting that the production of volatiles was accelerated in the second half of the experiment. It should be mentioned, that all the reported weight losses were normalized according to the water content loss.

According to the UV-VIS analysis conducted on the AO containing IL mixture, a significant absorption at $400 \mathrm{~nm}$ (violet range) was detected together with a weaker one at $580 \mathrm{~nm}$ (orange range), indicating that more than one molecular change occurred. Based on the UV-VIS data, the colour intensity of AEP $1000 \mathrm{mM}$ after the $7^{\text {th }}$ day of alteration was qualitatively brighter compared to the one of the AO containing IL mixture (Fig. S2 from the ESI $\dagger$ ). A brighter colour is indicative for a slightly better thermo-oxidative stability, as shown in Fig. 2 and 3.

No changes in the FTIR spectra have been detected for the phosphonium phosphate IL after the $7^{\text {th }}$ day of thermooxidative stress, confirming its superior stability (Fig. S3, in 
ESI $\dagger$ ). On the other hand, in the case of the imidazole based ILs, major changes concerning intensity and band positions were observed (Fig. S3b and $\mathrm{c}^{\dagger}$ ). The number of $\mathrm{C}-\mathrm{H}$ stretching vibration bands $\left(2802 \mathrm{~cm}^{-1}\right.$ to $\left.2950 \mathrm{~cm}^{-1}\right)$ diminished from five to three, while the band intensities decreased significantly. The finger print region changed dramatically for both ILs as a result of molecular changes. In case of $N$-allylimidazole based IL, a hint of oxidation $(\mathrm{C}=\mathrm{O}$ band) was detected based on a weak signal present at $1710 \mathrm{~cm}^{-1}$.

Regarding the AEP $100 \mathrm{mM}$ mixture, an overall decrease in the intensity for the $\mathrm{C}-\mathrm{H}$ stretching vibration bands $\left(2802 \mathrm{~cm}^{-1}\right.$ to $2950 \mathrm{~cm}^{-1}$ ) was observed throughout the artificial alteration, regardless of the number of sampling days (Fig. 4a). The band corresponding to carbonyl group $\left(\mathrm{C}=\mathrm{O}\right.$ at $\left.1710 \mathrm{~cm}^{-1}\right)$ was also detected for this mixture. An increase in the bands' intensity in the fingerprint region $\left(900 \mathrm{~cm}^{-1}\right.$ to $\left.1500 \mathrm{~cm}^{-1}\right)$ is indicative for the decomposition of the ILs that may lead to volatiles formation as seen in the weight loss data (Fig. 3).

The carbonyl band $(\mathrm{C}=\mathrm{O})$ was absent in case of the AEP $1000 \mathrm{mM}$ mixture (Fig. 4b). Only a small neighbouring peak at $\sim 1647 \mathrm{~cm}^{-1}$ which could be attributed to increased $\mathrm{C}=\mathrm{C}$ band formation was detected for the sample exposed to artificial alteration for 7 days. Moreover, the $\mathrm{C}-\mathrm{H}$ stretching vibration bands $\left(2802 \mathrm{~cm}^{-1}\right.$ to $\left.2950 \mathrm{~cm}^{-1}\right)$ appear not to decrease over time, thus supporting the lower weight loss results obtained for this mixture in comparison to AEP $100 \mathrm{mM}$ (Fig. 3). The
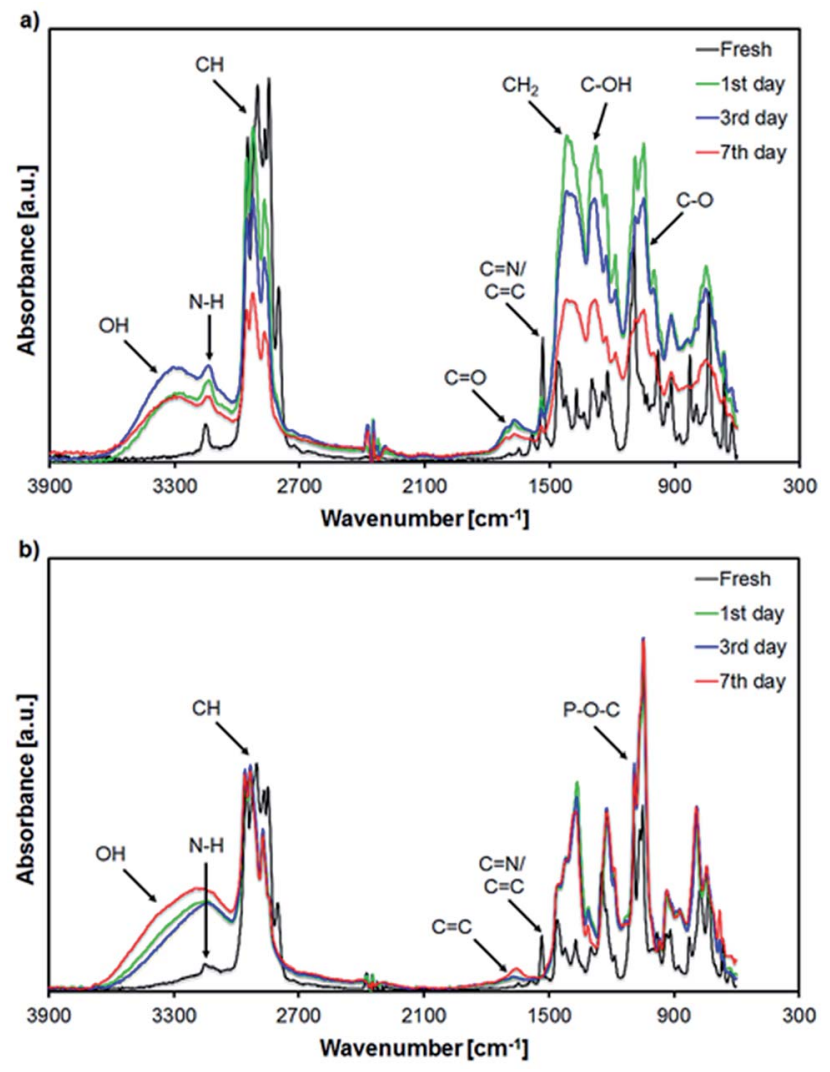

Fig. 4 FTIR spectra of AEP $100 \mathrm{mM}$ (a) and AEP $1000 \mathrm{mM}$ (b) mixtures: fresh and exposed to artificial alteration experiments for 1, 3 and 7 days. fingerprint region was characterized by the appearance of P-O-C deformations vibrations $\left(1049 \mathrm{~cm}^{-1}\right.$ and $1087 \mathrm{~cm}^{-1}$ ) which are characteristic for the phosphate based ILs, ${ }^{58}$ as well as slight changes in molecular structures highlighted by the slight increase in the intensity of the bands detected in this region.

Regarding the other two mixtures (AEP $1000 \mathrm{mM}+\mathrm{AO}$ $100 \mathrm{mM}$ and AEP $1000 \mathrm{mM}+50 \mathrm{FM}$ ), no significant changes have been detected in the FTIR spectra in comparison to the spectrum of the AEP $1000 \mathrm{mM}$ mixture. This could be attributed to the low content of AO and FM additives. The FTIR spectra of these mixtures are included in the ESI (Fig. S4a and $\mathrm{b} \dagger$ ).

\subsection{Tribo-evaluation of ionic liquids}

A well pronounced running-in, followed by a slight decrease in friction and culminating with the failure of the lubricant film were characteristic for the $\operatorname{AE}(1: 1)$ additive-free mixture (Fig. 5). This was highlighted by the sudden increase in friction after approximately 50 minutes. As expected, the decrease in the viscosity at elevated temperature had a negative impact on the tribological performance of this mixture, leading to a decrease in the lubricant film thickness. As a consequence, an increase in the area of metal asperity contacts caused a sharp rise in friction. ${ }^{30}$ It is well known that in case of low viscosity lubricants, the conditions between the moving parts are harsher due to the increased temperature from the higher friction. Therefore, the large instabilities in friction observed for the $\mathrm{AE}(1: 1)$ additivefree mixture are similar to a behavior of a dry contact between the moving parts and can be attributed to the boundary lubricant failure.

The addition of $100 \mathrm{mM}$ of $\mathrm{P}$ additive slightly improved the first $300 \mathrm{~s}$ of the running-in but led to an unstable friction outlined by the partial seizures observed for the AEP $100 \mathrm{mM}$ mixture in Fig. 5. This result indicates that $\mathrm{P}$ concentration was too low for an overall improvement in friction under these conditions. On the other hand, a 10 fold increase in the $\mathrm{P}$ additive concentration led to a significant improvement in the running-in as well as in the overall friction which decreased to a steady-state value of 0.08 . Furthermore, the addition of either $100 \mathrm{mM}$ of AO or $50 \mathrm{mM}$ of FM to the AEP $1000 \mathrm{mM}$ mixture led to similar results showing a smooth running-in and a relative stable but slightly higher friction with only a few partial seizures as compared to the AEP $1000 \mathrm{mM}$ mixture alone.

Overall, the friction results show that an increase in the $\mathrm{P}$ concentration for the $\mathrm{AE}(1: 1)$ mixture was beneficial in providing a sufficient load-carrying capacity to separate the rubbing parts while facilitating the reaction of the phosphonium phosphate IL with the metal surface. ${ }^{54}$ As previously reported, when a metal surface is lubricated by IL, a layer structured film is formed initially by physical adsorption. ${ }^{55}$ The anions react first with the positively charged metal surface to form a layer composed of iron phosphates. It is therefore suggested that the formation of a multi-layer tribofilm that possess low traction at the interface under sliding was responsible for the reduced friction in case of the $\mathrm{AE}$ mixtures formulated with phosphonium phosphate. 

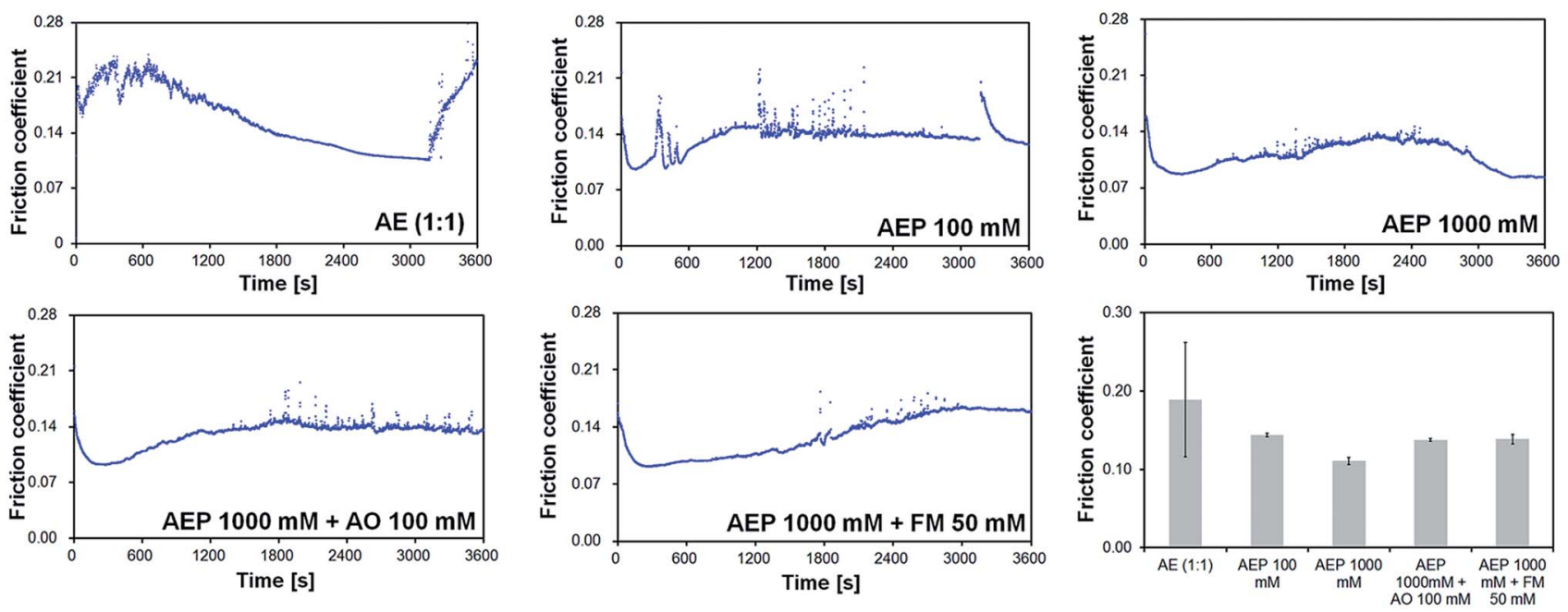

Fig. 5 Friction curves and average friction coefficients taken after the running-in period (>1200 s).

The effectiveness of the additives in terms of anti-wear properties shows even more outstanding results which are displayed in Fig. 6 . The disc wear volume decreased by 1 order of magnitude for the AEP $100 \mathrm{mM}$, AEP $1000 \mathrm{mM}$ and AEP $1000 \mathrm{mM}+\mathrm{AO} 100 \mathrm{mM}$ mixtures in comparison to the additivefree $\mathrm{AE}(1: 1)$ mixture. Moreover, the disc wear volume further decreased by a total of 2 orders of magnitude when FM $50 \mathrm{mM}$ was added into the AEP $1000 \mathrm{mM}$ mixture. A summary of the total wear volume of both counterparts is presented in the ESI (Fig. S5). $\dagger$ The wear scar topographies on the balls are shown in Fig. S6. $\dagger$

The wear results are further confirmed by the surface topographies of the discs lubricated with the $\mathrm{AE}(1: 1)$ additivefree mixture and the ones containing $\mathrm{AO}, \mathrm{FM}$ and $\mathrm{P}$ at various concentrations (Fig. 7). A large and deep wear scar dominated by severe abrasive wear can be observed for the surface lubricated with the additive-free $\mathrm{AE}(1: 1)$ mixture. This could be attributed to the high fluctuations in friction recorded during the running-in period.

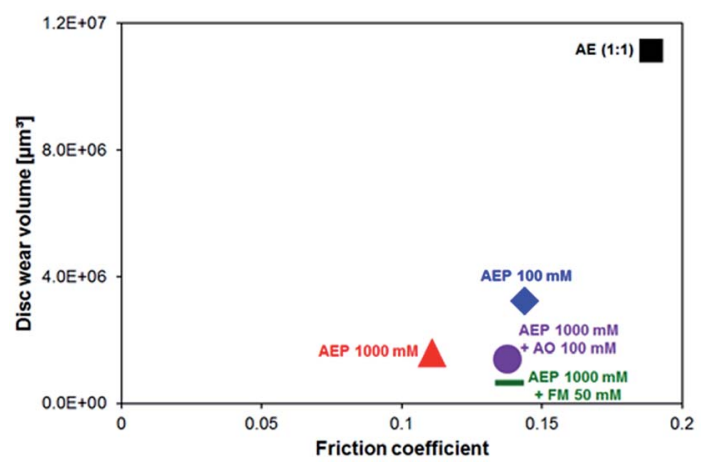

Fig. 6 Average disc wear volume versus average friction coefficient of the steel surfaces lubricated with AE (1:1); AEP $100 \mathrm{mM}$; AEP $1000 \mathrm{mM}$; AEP $1000 \mathrm{mM}+\mathrm{AO} 100 \mathrm{mM}$ and AEP $1000 \mathrm{mM}+\mathrm{FM}$ $50 \mathrm{mM}$.
On the other hand, the wear scars generated on the surfaces lubricated with the mixtures containing $\mathrm{P}$ at various concentrations were comparatively smaller. This clearly indicates that under these conditions, the phosphonium phosphate IL was instrumental in improving the anti-wear properties of the alkylborane-imidazole mixture. ${ }^{33}$ Moreover, a smooth surface, almost free of abrasion grooves could be detected in case of AEP $1000 \mathrm{mM}+\mathrm{FM} 50 \mathrm{mM}$ mixture. This could be attributed to a synergistic effect between the FM and the phosphonium phosphate IL on the disc. Due to the presence of two hydroxyl groups at the terminal of its molecule, the friction modifier could be adsorbed onto the metal surface thereby providing an extra wear protection. ${ }^{54}$ The different frictional and wear behaviours of the evaluated mixtures could be related to the chemical composition of the formed tribofilms which will be discussed within the next section.

\subsection{Chemical composition of the tribofilms}

In order to characterize the surface chemistry, XPS spot analyses were conducted in the middle of the wear scars of the discs lubricated with AE (1: 1), AEP $100 \mathrm{mM}$, AEP $1000 \mathrm{mM}$ and AEP $1000 \mathrm{mM}+$ FM $50 \mathrm{mM}$ mixtures. The XPS spectra were acquired after 20 seconds of fine sputtering which was conducted in order to remove any possible hydrocarbon contamination.

The high resolution XPS spectrum of B 1s from AE (1:1) mixture shows the presence of boron oxides at a binding energy of $191.2 \mathrm{eV}$ (ref. 32 and 33) (Fig. S7 in the ESI†). It has been reported that boron oxides readily formed from orthoborate based compounds improve tribological properties of the rubbing surfaces. ${ }^{42-44}$ However, in case of tributylborane compounds, a two-step chemical reaction for boundary film formation is suspected; (1) elimination of the butyl group, and (2) oxidation of boron, thus suggesting a slow generation of boundary film. The lubricant failure occurred after almost 3000 seconds was probably due to insufficient formation of boundary film. 


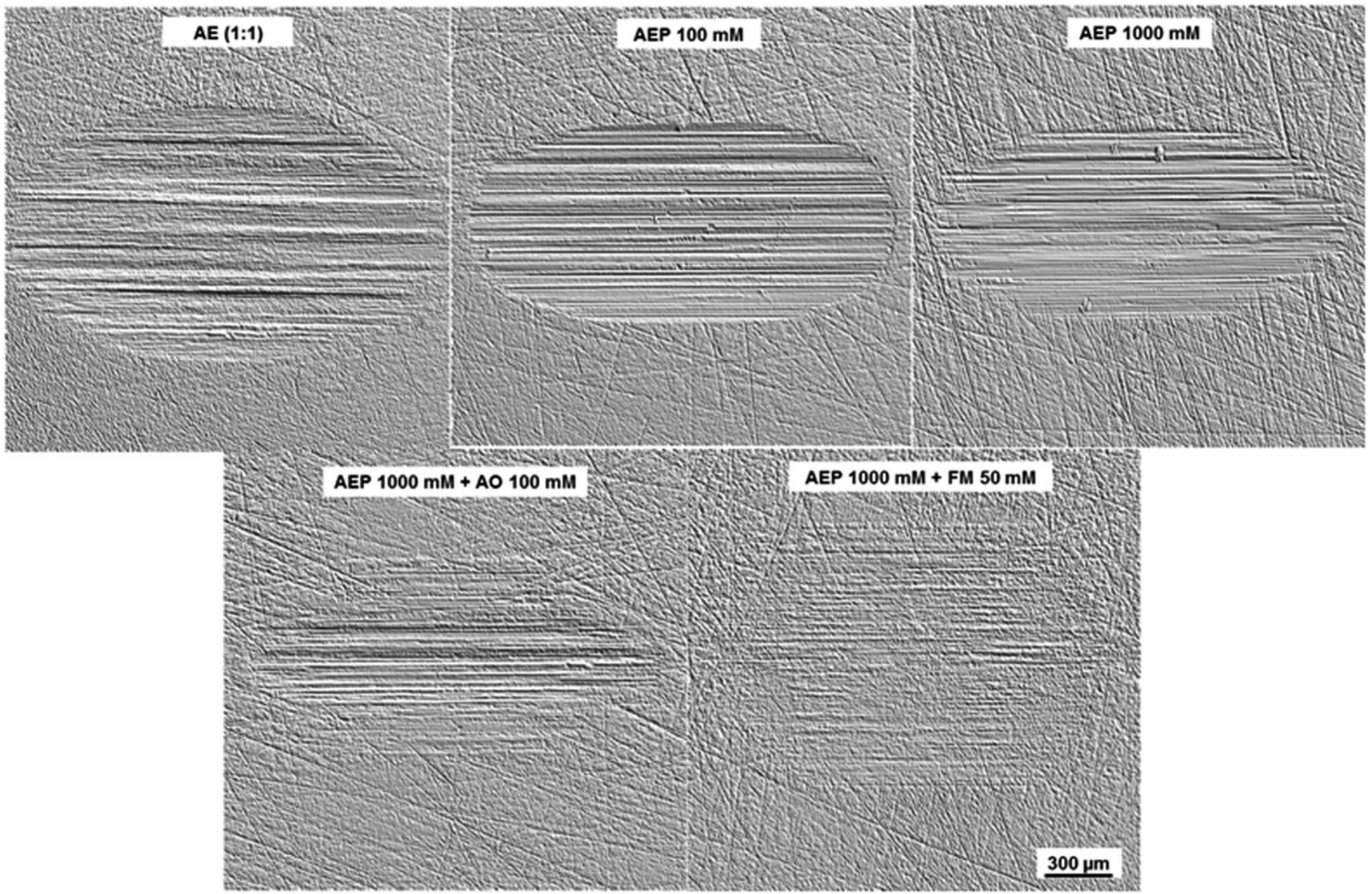

Fig. 7 Topography images of worn disc surfaces lubricated with AE (1: 1); AEP 100 mM; AEP 1000 mM; AEP 1000 mM + AO 100 mM and AEP $1000 \mathrm{mM}$ + FM $50 \mathrm{mM}$.

Fig. 8 shows the $\mathrm{P} 2 \mathrm{p}$ spectra of the $\mathrm{P}$ containing $\mathrm{AE}(1: 1)$ mixtures. Two obvious contributions could be detected for the AEP $1000 \mathrm{mM}$ + FM $50 \mathrm{mM}$ (top) and AEP $1000 \mathrm{mM}$ (middle) mixtures. According to prior findings, the first one at $129.2 \mathrm{eV}$ is attributed to iron phosphide ${ }^{51,59}$ whereas the second one at $133.3 \mathrm{eV}$ is attributed to iron phosphate. ${ }^{32,33}$ Regarding AEP $100 \mathrm{mM}$, only one obvious contribution of iron phosphate $(133.3 \mathrm{eV})$ could be detected in the P 2p spectrum (Fig. 8, bottom). Due to high level of noise compared to the signal, it is rather difficult to detect the formation of iron phosphide in this case.

As to the mixtures with higher $\mathrm{P}$ content $(1000 \mathrm{mM})$, it should be mentioned that this is the very first study reporting on the formation of iron phosphide species from phosphonium phosphate ILs. While most of the literature reported on formation of iron phosphate tribofilms as a result of a tribochemical reaction of phosphate anion with iron surfaces, it is believed that in this current study, the reaction of the phosphonium cation with the nascent tribo-stressed metal surface could be at the origin of the suspected formation of iron phosphide.

The hard and soft acid base (HSAB) principle of Pearson can be used to explain the tribochemical reactions. ${ }^{60}$ According to this principle, "a hard base prefers to react with a hard acid and a soft base with a soft acid". In our case, the pyrolysis of tetraalkyl phosphonium cation yields trialkyl phosphine which is a soft base, phosphate anion is a hard base, metallic iron a soft acid, and iron oxide a hard acid. It is therefore hypothesized that the trialkylphosphine will react preferentially with metallic iron to form iron phosphide and phosphate will react with iron oxide to form iron phosphate.

According to the friction and wear results from the previous section, the formation of iron phosphide tribofilms was beneficial in improving the tribological performance of the tribosystem. This is further highlighted in Table 3 and Fig. 9 where an increase in the overall relative surface atomic concentration of $\mathrm{P} 2 \mathrm{p}$ is correlated with an improvement in the anti-wear properties exhibited by the AEP $1000 \mathrm{mM}+\mathrm{FM} 50 \mathrm{mM}$ mixture on the disc surface.

\subsection{Tribofilm formation}

Based on the XPS analyses, the differences in composition of the tribofilms formed on the steel substrates are illustrated in Fig. 9.

According to XPS, the tribofilms formed on the steel surface rubbed with the mixture containing the FM are composed of a mixture of iron phosphate (9.7 at\%) and iron phosphide (6.4 at\%). Additionally, a mono-molecular layer (possibly removed during sputtering) coming from the FM adsorbed on the steel surface completes the structure of this tribofilm. According to 

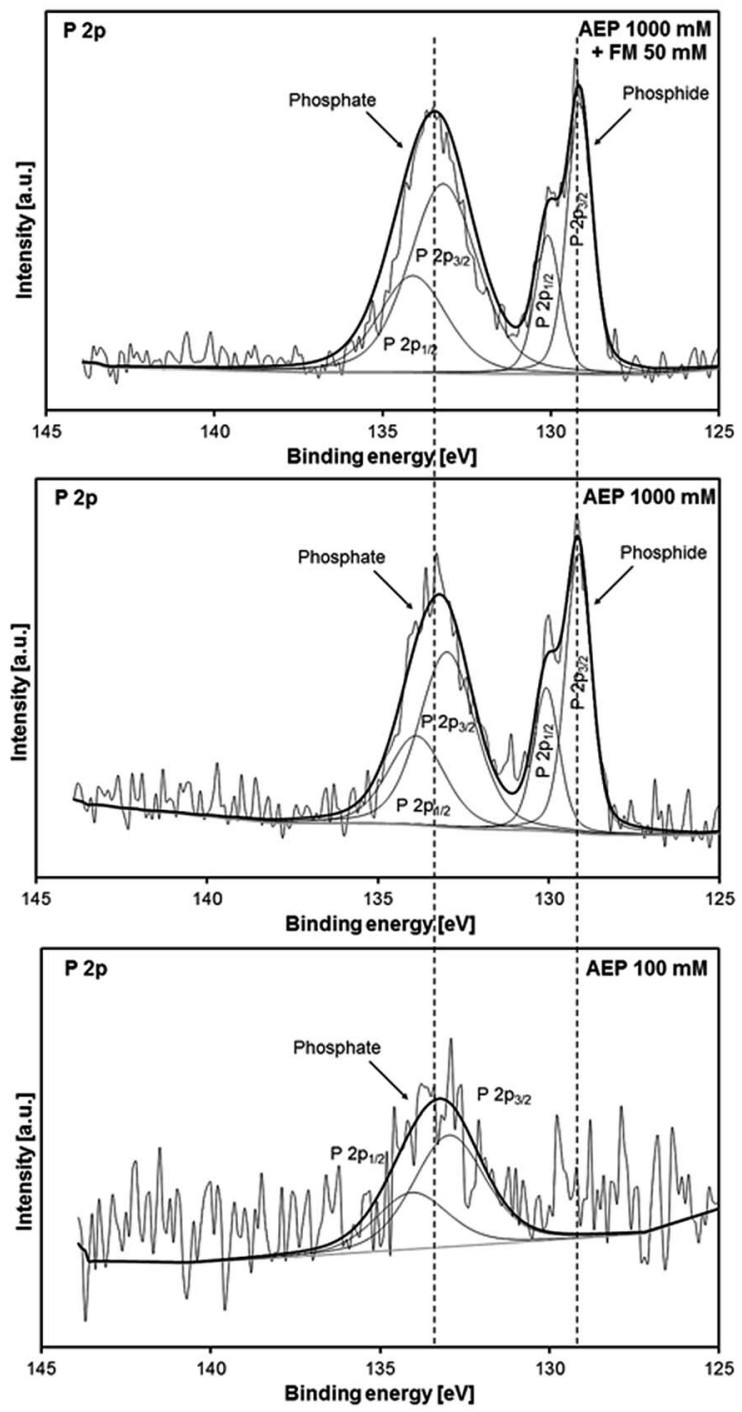

Fig. 8 High resolution XPS spectra of P $2 p$ for $P$ containing mixtures.

Table 3 Surface atomic concentrations of elements inside the middle of the disc wear scar as acquired by XPS survey scans

\begin{tabular}{lrllllll}
\hline & \multicolumn{6}{c}{ Element concentration (atomic\%) } \\
\cline { 2 - 7 } Sample & C 1s & O 1s & N 1s & Fe 2p & B 1s & P 2p \\
\hline AE $(1: 1)$ & 50.6 & 35.0 & 5.1 & 5.5 & 3.6 & - \\
AEP 100 mM & 7.4 & 51.9 & 2.9 & 28.3 & - & 5.2 \\
AEP 1000 mM & 49.8 & 24.5 & - & 12.1 & - & 9.7 \\
AEP 1000 mM + FM 50 mM & 8.6 & 42.4 & - & 36.4 & - & 11.4
\end{tabular}

prior findings, the thickness of this mono-molecular layer is less than $2 \mathrm{~nm}$, as observed by TOF-SIMS analysis. ${ }^{61,62}$

The tribofilm detected on the surface rubbed with the AEP $1000 \mathrm{mM}$ mixture was also composed of a mixture of iron phosphate ( 4.9 at\%) and iron phosphide (3.6 at\%) but the lower quantities found for these species led to a poorer tribological performance of the AEP $1000 \mathrm{mM}$ mixture when compared to AEP $1000 \mathrm{mM}+$ FM $50 \mathrm{mM}$ regarding the disc surfaces.

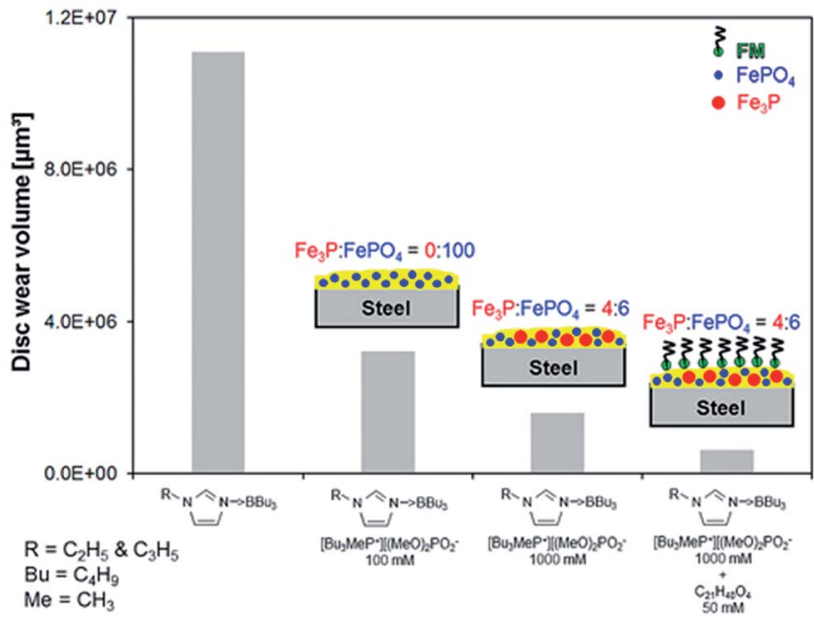

Fig. 9 Schematics of tribofilm structures produced by AEP $100 \mathrm{mM}$, AEP $1000 \mathrm{mM}$ and AEP $1000 \mathrm{mM}$ + FM 50 mM, and their contribution on disc wear reduction.

Finally, the tribofilms detected on the steel disc surface rubbed with AEP $100 \mathrm{mM}$ mixture consisted mainly of iron phosphate (2.5 at\%). The lack of iron phosphide associated with the lowest amount of iron phosphate could be indicative for the insufficient tribological performance exhibited by this mixture.

\section{Conclusions}

This work revealed further insights into thermo-oxidative stability and tribochemistry of phosphonium phosphate IL in alkylborane-imidazole complexes. The thermo-oxidative stability assessment showed that a careful selection of an appropriate carrier fluid and IL additive are crucial when it comes to formulation of IL-based lubricants.

On the other hand, the phosphonium phosphate IL proved to significantly enhance both thermo-oxidative stability and tribological performance of the alkylborane-imidazole complexes. The friction and wear behavior was correlated with fundamental changes in the tribofilm's composition that had a positive impact on the ILs tribological performance at elevated temperatures. In this context, clear evidences for the formation of iron phosphide based tribofilms from phosphonium phosphate IL have been reported for the first time.

Additionally, a beneficial effect between the phosphonium phosphate and a conventional friction modifier led to improved anti-wear properties of the disc surfaces supported by the presence of iron phosphide and phosphate tribofilms, as detected by XPS.

The current findings can be extended to optimize lubricant formulations that are exclusively based on ionic liquids, thus providing a step forward towards a more novel lubrication approach focused on the molecular design of RTIL-based lubricants.

\section{Conflicts of interest}

There are no conflicts to declare. 


\section{Acknowledgements}

This work was funded by the Austrian COMET-Program (Project K2 XTribology, Grant No. 849109) and has been carried out within the Excellence Centre of Tribology. Also, part of this work was funded within the FP7 program - Marie Curie Initial Training Network MINILUBES [216011-2] - by the European Commission. Preliminary work on this project was supported by KAKENHI (Grant No. 23246030). The authors would like to thank Christoph Gabler for performing the XPS analyses.

\section{References}

1 C. Ye, W. Liu, Y. Chen and L. Yu, Room-temperature ionic liquids: a novel versatile lubricant, Chem. Commun., 2001, 21, 2244-2245.

2 I. Minami, Ionic liquids in tribology, Molecules, 2009, 14, 2286-2305.

3 F. Zhou, Y. M. Liang and W. M. Liu, Ionic liquid lubricants: designed chemistry for engineering applications, Chem. Soc. Rev., 2009, 28, 2590-2599.

4 M. D. Bermudez, A. E. Jimenez, J. Sanes and F. J. Carrion, Ionic liquids as advanced lubricant fluids, Molecules, 2009, 14, 2888-2908.

5 T. Torimoto, T. Tsuda, K. Okazaki and S. Kuwawata, New frontiers in materials science opened by ionic liquids, Adv. Mater., 2010, 22, 1196-1221.

6 A. E. Somers, P. C. Howlett, D. R. MacFarlane and M. Forsyth, A review of ionic liquid lubricants, Lubricants, 2013, 1, 3-21.

7 J. Qu, W. C. Barnhill, H. Luo, H. M. Meyer III, D. N. Leonard, A. K. Landauer, B. Kheireddin, H. Gao, B. L. Papke and S. Dai, Synergistic Effects Between PhosphoniumAlkylphosphate Ionic Liquids and Zinc Dialkyldithiophosphate (ZDDP) as Lubricant Additives, $A d v$. Mater., 2015, 27, 4767-4774.

8 B. S. Phillips, G. John and J. S. Zabinski, Surface chemistry of fluorine containing ionic liquids on steel substrates at elevated temperature using Mössbauer spectroscopy, Tribol. Lett., 2007, 26, 85-91.

9 N. Canter, Using dicationic liquids as high temperature lubricants, Tribol. Lubr. Technol., 2007, 63, 12-13.

10 A. E. Jimenez and M. D. Bermudez, Ionic liquids as lubricants of titanium-steel contact part 2: friction, wear and surface interactions at high temperature, Tribol. Lett., 2010, 37, 431-443.

11 V. Totolin, N. Ranetcaia, V. Hamciuc, N. Shore, N. Dörr, C. Ibanescu, B. C. Simionescu and V. Harabagiu, Influence of ionic structure on tribological properties of poly(dimethylsiloxane-alkylene oxide) graft copolymers, Tribol. Int., 2013, 67, 1-10.

12 A. Suzuki, Y. Shinka and M. Masuko, Tribological characteristics of imidazolium-based room temperature ionic liquids under high vacuum, Tribol. Lett., 2007, 24, 307-313.

13 T. Yagi, S. Sasaki, H. Mano, K. Miyake, M. Nakano and T. Ishida, Lubricity and chemical reactivity of ionic liquid used for sliding metals under high-vacuum conditions, Proc. Inst. Mech. Eng., Part J, 2009, 223, 1083-1090.

14 V. Totolin, M. Conte, E. Berriozábal, F. Pagano, I. Minami, N. Dörr, J. Brenner and A. Igartua, Tribological Investigations of Ionic Liquids in Ultra-high Vacuum Environment, Lubr. Sci., 2014, 26, 514-524.

15 R. P. Swatloski, J. D. Holbrey and R. D. Rogers, Ionic liquids are not always green: hydrolysis of 1-butyl-3methylimidazolium hexafluorophosphate, Green Chem., 2003, 5, 361-363.

16 M. Yao, Y. Liang, Y. Xia and F. Zhou, Bisimidazolium Ionic Liquids as the High-Performance Antiwear Additives in Poly(ethylene glycol) for Steel-Steel Contacts, ACS Appl. Mater. Interfaces, 2009, 1, 467-471.

17 M. Cai, Y. Liang, M. Yao, Y. Xia, F. Zhou and W. Liu, Imidazolium ionic liquids as antiwear and antioxidant additive in poly(ethylene glycol) for steel/steel contacts, ACS Appl. Mater. Interfaces, 2010, 2, 870-876.

18 I. Minami, T. Inada, R. Sasaki and H. Nanao, TriboChemistry of Phosphonium-Derived Ionic Liquids, Tribol. Lett., 2010, 40, 225-235.

19 M. Kronberger, V. Pejaković, C. Gabler and M. Kalin, How anion and cation species influence the tribology of a green lubricant based on ionic liquids, Proc. Inst. Mech. Eng., Part $J$, 2012, 226, 933-951.

20 V. Pejaković, M. Kronberger, M. Mahrova, M. Vilas, E. Tojo and M. Kalin, Pyrrolidinium sulfate and ammonium sulfate ionic liquids as lubricant additives for steel/steel contact lubrication, Proc. Inst. Mech. Eng., Part J, 2012, 226, 923-932.

21 V. Pejaković, M. Kronberger and M. Kalin, Influence of temperature on tribological behaviour of ionic liquids as lubricants and lubricant additives, Lubr. Sci., 2014, 26, 107-115.

22 I. Minami, H. Kamimura and S. Mori, Thermo-oxidative stability of ionic liquids as lubricating fluids, J. Synth. Lubr., 2007, 24, 135-147.

23 L. Pisarova, C. Gabler, N. Dörr, E. Pittenauer and G. Allmaier, Thermo-oxidative stability and corrosion properties of ammonium based ionic liquids, Tribol. Int., 2012, 46, 73-83.

24 L. Pisarova, V. Totolin, C. Gabler, N. Dörr, E. Pittenauer, G. Allmaier and I. Minami, Insight into degradation of ammonium-based ionic liquids and comparison of tribological performance between selected intact and altered ionic liquid, Tribol. Int., 2013, 65, 13-27.

25 C. Gabler, C. Tomastik, J. Brenner, L. Pisarova, N. Dörr and G. Allmaier, Corrosion properties of ammonium based ionic liquids evaluated by SEM-EDX, XPS and ICP-OES, Green Chem., 2011, 13, 2869-2877.

26 N. Saurin, I. Minami, J. Sanes and M. D. Bermudez, Study of the effect of tribo-materials and surface finish on the lubricant performance of new halogen-free room temperature ionic liquids, Appl. Surf. Sci., 2016, 366, 464474.

27 I. Minami, M. Kita, T. Kubo, H. Nanao and S. Mori, The tribological properties of ionic liquids composed of trifluorotris(pentafluoroethyl) phosphate as a hydrophobic anion, Tribol. Lett., 2008, 30, 215-223. 
28 M. D. Bermudez and A. E. Jimenez, Surface interactions and tribochemical processes in ionic liquid lubrication of aluminium steel contacts, Int. J. Surf. Sci. Eng., 2007, 1, 100-110.

29 I. Minami, T. Inada and Y. Okada, Tribological properties of halogen-free ionic liquids, Proc. Inst. Mech. Eng., Part J, 2012, 226(11), 891-902.

30 A. E. Somers, S. M. Biddulph, P. C. Howlett, J. Sun, D. R. MacFarlane and M. Forsyth, A comparison of phosphorus and fluorine containing IL lubricants for steel on aluminium, Phys. Chem. Chem. Phys., 2012, 14, 82248231.

31 F. U. Shah, S. Glavatskih, E. Höglund, M. Lindberg and O. N. Antzutkin, Interfacial Antiwear and Physicochemical Properties of Alkylborate-dithiophosphates, ACS Appl. Mater. Interfaces, 2011, 3, 956-968.

32 V. Totolin, I. Minami, C. Gabler and N. Dörr, Halogen-free borate ionic liquids as novel lubricants for tribological applications, Tribol. Int., 2013, 67, 191-198.

33 V. Totolin, I. Minami, C. Gabler, J. Brenner and N. Dörr, Lubrication mechanism of phosphonium phosphate ionic liquid additive in alkylborane-imidazole complexes, Tribol. Lett. , 2014, 53(2), 421-432.

34 N. Matsumi, A. Mori, K. Sakamoto and H. Ohno, Liquid imidazole-borane complex, Chem. Commun., 2005, 36, 4557-4559.

35 B. Yu, D. G. Bansal, J. Qu, X. Sun, H. Luo, S. Dai, P. J. Blau, B. G. Bunting, G. Mordukhovich and D. J. Smolenski, Oilmiscible and non-corrosive phosphonium-based ionic liquids as candidate lubricant additives, Wear, 2012, 289, 58-64.

36 J. Qu, H. Luo, M. Chi, C. Ma, P. J. Blau, S. Dai and M. B. Viola, Comparison of an oil-miscible ionic liquid and ZDDP as a lubricant anti-wear additive, Tribol. Int., 2014, 71, 88-97.

37 V. Sharma, N. Dörr and P. Aswath, Chemical-mechanical properties of tribofilms and their relationship to ionic liquid chemistry, RSC Adv., 2016, 6(27), 22341-22356.

38 J. Qu, D. G. Bansal, B. Yu, J. Y. Howe, H. Luo, S. Dai, H. Li, P. J. Blau, B. G. Bunting, G. Mordukhovich and D. J. Smolenski, Antiwear performance and mechanism of an oil-miscible ionic liquid as a lubricant additive, $A C S$ Appl. Mater. Interfaces, 2012, 4(2), 997-1002.

39 R. Gusain, R. Singh, K. L. N. Sivakumar and O. P. Khatri, Halogen-free imidazolium/ammoniumbis(salicylato)borate ionic liquids as high performance lubricant additives, $R S C$ Adv., 2014, 4, 1293-1301.

40 R. Gusain and O. P. Khatri, Halogen-free ionic liquids: effect of chelated orthoborate anion structure on their lubrication properties, RSC Adv., 2015, 5, 25287-25294.

$41 \mathrm{R}$. Gusain and O. P. Khatri, Fatty acid ionic liquids as environmentally friendly lubricants for low friction and wear, RSC Adv., 2016, 6, 3462-3469.

42 D. Philippon, M. I. De Barros-Bouchet, O. Lerasle, T. L. Mogne and J. M. Martin, Experimental simulation of tribochemical reactions between borates esters and steel surface, Tribol. Lett., 2011, 41, 73-82.
43 V. Sharma, N. Doerr, A. Erdemir and P. B. Aswath, Interaction of phosphonium ionic liquids with borate esters at tribological interfaces, RSC Adv., 2016, 6, 53148.

44 F. U. Shah, S. Glavatskih, D. R. MacFarlane, A. Somers, M. Forsyth and O. N. Antzutkin, Novel halogen-free chelated orthoborate-phosphonium ionic liquids: Synthesis and tribophysical properties, Phys. Chem. Chem. Phys., 2011, 13, 12865-12873.

45 A. Hernández Battez, M. Bartolomé, D. Blanco, J. L. Viesca, A. Fernández-González and R. González, Phosphonium cation-based ionic liquids as neat lubricants: Physicochemical and tribological performance, Tribol. Int., 2016, 95, 118-131.

46 P. K. Khatri, C. Joshi, G. D. Thakre and S. L. Jain, Halogenfree ammonium-organoborate ionic liquids as lubricating additives: The effect of alkyl chain lengths on the tribological performance, New J. Chem., 2016, 40, 5294-5299.

47 Z. Song, Y. Liang, M. Fan, F. Zhou and W. Liu, Ionic liquids from amino acids: Fully green fluid lubricants for various surface contacts, RSC Adv., 2014, 4(37), 19396-19402.

48 S. Sowmiah, V. Srinivasadesikan, M.-C. Tseng and Y.-H. Chu, On the Chemical Stabilities of Ionic Liquids, Molecules, 2009, 14, 3780-3813.

49 A. Riga, J. Cahoon and W. R. Pistillo, Organophosphorus chemistry structure and performance relationships in FZG gear tests, Tribol. Lett., 2001, 9(3), 219-225.

50 D. Philippon, M.-I. De Barros-Bouchet, T. Le Mogne, B. Vacher, O. Lerasle and J.-M. Martin, A multi-technique approach to the characterization of iron phosphide tribofilm, Thin Solid Films, 2012, 524, 191-196.

51 M. I. De Barros-Bouchet, M. C. Righi, D. Philippon, S. Mambingo-Doumbe, T. Le-Mogne, J. M. Martin and A. Bouffet, Tribochemistry of phosphorus additives: experiments and first-principles calculations, RSC Adv., 2015, 5, 49270.

52 H. Hunger, U. Litzow, S. Genze, N. Dörr, D. Karner and C. Eisenmenger-Sittner, Tribological characterisation and surface analysis of diesel lubricated sliding contacts, Proceedings TAE, ISBN 3-924813-73-6, TAE, Ostfildern, Germany, 2008.

53 S. Zhang, N. Sun, X. He, X. Lu and X. Zhang, Physical Properties of Ionic Liquids: Database and Evaluation, $J$. Phys. Chem. Ref. Data, 2006, 35, 1475-1517.

54 E. Nyberg, C. Y. Respatiningsih and I. Minami, Molecular design of advanced lubricant base fluids: hydrocarbonmimicking ionic liquids, $R S C A d v ., 2017,7,6364$.

55 G. Mordukhovich, J. Qu, J. Y. Howe, S. Bair, B. Yu, H. Luo, D. J. Smolenski, P. J. Blau, B. G. Bunting and S. Dai, A lowviscosity ionic liquid demonstrating superior lubricating performance from mixed to boundary lubrication, Wear, 2013, 301, 740-746.

56 L. Calvo, M. J. Cocero and J. M. Diez, Oxidative Stability of Sunflower Oil Extracted with Supercritical Carbon Dioxide, J. Am. Oil Chem. Soc., 1994, 71, 1251-1254.

57 G. Aguilar, G. Mazzamaro and M. Rasberger, Oxidative Degradation and Stabilisation of Mineral Oil-Based Lubricants, Chemistry and Technology of Lubricants, ed. 
R. M. Mortier, M. F. Fox and S. T. Orszulikin, Springer, Netherlands, 3rd edn, 2010.

58 I. Sedenkova, M. Trchova, J. Dybal and J. Stejskal, Interaction of polyaniline film with dibutyl phosphonate versus phosphite: Enhanced thermal stability, Polym. Degrad. Stab., 2016, 134, 357-365.

59 D. Philippon, M.-I. DeBarros-Bouchet, T. LeMogne, O. Lerasle, A. Bouffet and J.-M. Martin, Role of nascent metallic surfaces on the tribochemistry of phosphite lubricant additives, Tribol. Int., 2011, 44, 684-691.
60 R. G. Pearson, Hard and soft acid base, J. Am. Chem. Soc., 1963, 85(22), 3533.

61 I. Minami, T. Kubo, H. Nanao, S. Mori, T. Sagawa and S. Okuda, Investigation of Tribo-Chemistry by Means of Stable Isotopic Tracers, Part 2: Lubrication Mechanism of Friction Modifiers on Diamond-Like Carbon, Tribol. Trans., 2007, 50, 477-487.

62 I. Minami, T. Furesawa, T. Kubo, H. Nanao and S. Mori, Investigation of tribo-chemistry by means of stable isotopic tracers: Mechanism for durability of monomolecular boundary film, Tribol. Int., 2008, 41, 1056-1062. 